\title{
STRATEGI ALOKASI ANGGARAN SEKTOR PERTANIAN UNTUK MEMPERCEPAT PEMBANGUNAN DAERAH DI KABUPATEN PANDEGLANG PROVINSI BANTEN
}

\author{
Budget Alocation Strategy of Agricultural Sector for accelerating Local Development in \\ Pandeglang Distric, Banten Province
}

\section{Eling Sri Wahyuni', Muhammad Firdaus², Lukman Mohammad Baga²}

${ }^{1}$ Staff Biro Perencanaan dan Keuangan, Sekretariat Jenderal Kementerian Keuangan RI. Email: elingsriwahyuni@gmail.com

${ }^{2}$ Staff Pengajar Departemen Ilmu Ekonomi, Fakultas Ekonomi dan Manajemen. IPB. Email: firdausfemipb@yahoo.com

${ }^{2}$ Staff Pengajar Departemen Agribisnis, Fakultas Ekonomi dan Manajemen. IPB. Email: lukmanmb@yahoo.com

\begin{abstract}
The agricultural sector is one of the leading sectors in Pandeglang Regency. This study aims to describe the process of preparing and implementing agricultural sector budgets, analyzing the effect of agricultural sector and labor of the agricultural sector expenditure toward the growth of the agricultural sector regionally in Banten Province, and then formulating appropriate strategies in budget allocation and agricultural sector development. This study uses secondary data and primary data with descriptive analysis tools, regression analysis using panel data, and SWOT analysis. The results showed that the agricultural sector has become a priority in various planning documents in Pandeglang District including RPJP, RPJMD, and RKPD Pandeglang District. Then from the result of regression analysis using panel data, it is resulted that government expenditure for agriculture sector have positive and significant effect toward PDRB of agriculture sector. Meanwhile, the labor of agricultural sector has negative and significant effect toward GDP of agriculture sector. From the results of objectives 1 and 2 and supported by primary data through in-depth interviews could be formulated 10 strategies of budget allocation and development of agricultural sector in Pandeglang Regency.
\end{abstract}

Keywords: Strategy, Agricultural Sector, Budget

\begin{abstract}
ABSTRAK
Sektor pertanian merupakan salah satu sektor unggulan di Kabupaten Pandeglang. Penelitian ini bertujuan untuk mendeskripsikan proses penyusunan dan implementasi anggaran sektor pertanian, menganalisis pengaruh pengeluaran sektor pertanian dan tenaga kerja sektor pertanian terhadap pertumbuhan sektor pertanian secara regional di Provinsi Banten, dan kemudian menyusun strategi yang tepat dalam alokasi anggaran dan pengembangan sektor pertanian. Penelitian ini menggunakan data sekunder dan data primer dengan alat analisis deskriptif, analisis regresi menggunakan data panel, dan analisis SWOT. Hasil penelitian menunjukkan bahwa sektor pertanian sudah menjadi prioritas dalam berbagai dokumen perencanaan di Kabupaten Pandeglang baik itu RPJP, RPJMD, maupun RKPD Kabupaten Pandeglang. Kemudian dari hasil analisis regresi menggunakan data panel, dihasilkan bahwa pengeluaran pemerintah sektor pertanian berpengaruh positif dan signifikan terhadap PDRB Sektor pertanian. Sementara itu tenaga kerja sektor pertanian berpengarug negatif dan signifikan terhadap PDRB sektor pertanian. Dari hasil tujuan 1 dan 2 serta dilengkapi dengan data primer melalui wawancara mendalam kemudian dirumuskan 10 strategi alokasi anggaran dan pengembangan sektor pertanian di Kabupaten Pandeglang.
\end{abstract}

Kata Kunci : Strategi, Sektor Pertanian, Anggaran

\section{PENDAHULUAN}

Otonomi daerah dan desentralisasi fiskal diterapkan melalui UU No. 22 Tahun 1999 yang diperbaharui dengan undangundang terbaru yaitu UU No 9 Tahun 2015 tentang Pemerintahan Daerah, dan UU No.
25 Tahun 1999 yang diperbaharui dengan UU No 33 Tahun 2004 tentang Perimbangan Keuangan antara Pemerintah Pusat dan Daerah. Penyerahan wewenang kepada pemerintah daerah menjadi babak awal pengelolaan keuangan daerah oleh daerah masing-masing. Otonomi daerah 
dan desentralisasi fiskal menekankan pada pentingnya peran pemerintah daerah. Melalui pemetaan yang jelas terkait sumber daya yang dimiliki, pemerintah daerah akan dapat merumuskan kebijakan yang tepat. Pengelolaan pengeluaran daerah perlu dilakukan agar belanja daerah dapat sesuai dengan sasaran pembangunan secara tepat pada sektor-sektor yang produktif sehingga mampu memberikan dampak pada sektorsektor lainnya (multiplier effect).

Kabupaten Pandeglang merupakan salah satu kabupaten di Provinsi Banten yang memiliki kemampuan fiskal rendah. Selain itu Kabupaten Pandeglang termasuk dalam klasifikasi daerah tertinggal menurut RPJMN tahun 2010-2014. Adapun yang menjadi kriteria daerah tertinggal menurut Kementerian PDT diantaranya meliputi perekonomian masyarakat, sumberdaya manusia, prasarana, kemampuan keuangan lokal, aksesibilitas, dan karakteristik daerah (RPJMN 2010-2014, 2010). Nilai PDRB Per Kapita Kabupaten Pandeglang juga masih kecil jika dibandingkan dengan kabupaten lainnya di Provinsi Banten.

Sektor pertanian masih menjadi sektor unggulan di Kabupaten Pandeglang. Jika dilihat dari kontribusi terhadap PDRB di Kabupaten Pandeglang, sektor pertanian memberikan kontribusi yang paling besar jika dibandingkan dengan sektor lainnya yaitu sebesar 34\% pada tahun 2015 (BPS Pandeglang, 2016). Potensi pertanian di Kabupaten Pandeglang sangat baik dan produktif untuk dijadikan sektor unggulan. Selain itu, Kabupaten Pandeglang juga merupakan lumbung pangan di Provinsi Banten yang ikut menentukan ketahanan pangan secara regional.

Jika dilihat dari struktur tenaga kerja, mayoritas penduduk Kabupaten Pandeglang bekerja pada sektor pertanian. Sebanyak $42 \%$ tenaga kerja yang bergerak pada sektor pertanian. Hal tersebut menandakan sektor pertanian merupakan sektor yang produktif untuk dikembangan dan untuk mempercepat pembangunan ekonomi di Kabupaten Pandeglang.

Dilihat dari kontribusi PDRB maupun tenaga kerja, sektor unggulan di Kabupaten
Pandeglang adalah sektor pertanian. Untuk dapat mempercepat pembangunan di Kabupaten Pandeglang, mengembangkan sektor unggulan menjadi pilihan yang baik dalam penentuan prioritas alokasi anggaran. Oleh karena itu sangat menarik untuk melakukan penelitian terkait bagaimana strategi alokasi anggaran sektor pertanian untuk mempercepat pembangunan di Kabupaten Pandeglang?

Tujuan dari penelitian ini adalah : (1) Mendeskripsikan penyusunan anggaran dan pelaksanaan anggaran dan kinerja Pemerintah Kabupaten Pandeglang dan kesesuaiannya dengan sektor pertanian sebagai sektor unggulan; (2) Menganalisis pengaruh pengeluaran pemerintah sektor pertanian terhadap pertumbuhan sektor pertanian dan membandingkannya secara regional di Provinsi Banten

Merumuskan strategi alokasi anggaran dan program pengembangan sektor pertanian di Kabupaten Pandeglang.

\section{METODE PENELITIAN}

\section{Jenis dan Sumber Data}

Penelitian dilakukan di Kabupaten Pandeglang Provinsi Banten pada bulan Maret - Mei 2017. Jenis data yang digunakan dalam penelitian ini terdiri dari data primer dan data sekunder. Data primer diperoleh dengan cara observasi langsung, dan wawancara terhadap pihak eksekutif pemerintah daerah yaitu Badan Perencanaan Pembangunan Daerah (Bappeda), Badan Pengelola Keuangan Daerah (BPKD), perwakilan dinas terkait sektor pertanian yaitu Dinas Pertanian dan Perkebunan, dan pihak legislatif (Komisi II DPRD yang menangani bidang keuangan, perekonomian dan aset). Data sekunder berasal dari DJPK, BPKD, Bappeda, BPS maupun instansi terkait.

\section{Metode Analisis Data}

Alat analisis yang digunakan sesuai dengan urutan tujuan dalam penelitian ini adalah: (1) analisis deskriptif, (2) analisis regresi berganda menggunakan data panel 
serta (3) analisis SWOT. Analisis deskiptif digunakan untuk mendesktipsikan proses penyusunan anggaran melalui bedah dokumen perencanaan dan realisassi anggaran maupun kinerja di Kabupaten Pandegang untuk melihat posisi sektor pertanian sebagai sektor unggulan. Analisis statistik deskriptif adalah statistik yang digunakan untuk menganalisis data dengan cara mendeskripsikan atau menggambarkan data yang telah terkumpul sebagaimana adanya tanpa bermaksud membuat kesimpulan yang berlaku umum atau generalisasi (Sugiono 2010).

Untuk menjawab pertanyaan kedua dilakukan dengan menggunakan analisis regresi berganda dengan menggunakan data panel. Data panel sendiri merupakan gabungan antara data cross section dengan data times series (Firdaus 2011). Penelitian ini akan menggunakan data pengeluaran pemerintah sektor pertanian yang telah di reklasifikasi dari anggaran per urusan di daerah dalam kurun waktu 10 tahun terakhir yaitu 2006-2015. Adapun regresi data panel dapat dimodelkan sebagai berikut:

$$
\operatorname{lnPDRBAgr}_{\text {it }}=\underset{\ln _{0}+\beta_{1} \operatorname{lnGovAgr}_{\text {it }}+\beta_{2}}{\beta_{\text {it }}+\varepsilon}
$$

Dimana:

$$
\begin{aligned}
& \text { PDRBAgr = PDRB Sektor Pertanian }(\mathrm{Rp} \\
& \text { Juta) } \\
& \text { GovAgr = Pengeluaran Pemerintah Sektor } \\
& \text { Pertanian (Rp Juta) } \\
& \text { TKAgr }=\text { Jumlah TK Sektor Pertanian } \\
& \text { (Orang) } \\
& \ln =\text { Logaritma } \\
& \beta_{0} \quad=\text { Konstanta } \\
& \beta_{1-2} \quad=\text { Koefisien Regresi } \\
& \varepsilon=\text { Error } \\
& =\text { Kabupaten } / \text { Kota di Provinsi } \\
& \text { Banten } \\
& \text { = waktu (tahun 2006-2015) }
\end{aligned}
$$

Kemudian untuk menjawab tujuan ketiga menggunakan analisis SWOT. Adalam analisis SWOT, identifikasi faktor internal yang terdiri dari kelebihan dan kekurangan dan faktor eksternal yang terdiri dari peluang dan ancaman menjadi sangat penting. Kemudian dari faktor-faktor tersebut ditentukan faktor mana yang merupakan kelebihan, kelemahan, peluang dan ancaman. Pernilaian terhadap faktor internal dan eksteranl tersebut dilakukan berdasarkan pernilaian dari informan yang tepat dan dan memiliki keahlian terhadap permasalahan yang diteliti. Kemudian langkah selanjutnya adalah mengkombinasikannya yang meliputi kombinasi internal eksternal menggunakan Matriks SWOT.

\section{HASIL DAN PEMBAHASAN}

\section{Penyusunan dan Implementasi Kebijakan di Sektor Pertanian}

Dalam dokumen perencanaan Pandeglang 2005-2025, sektor pertanian telah diangkat dalam beberapa hal yaitu sebagai potensi dan modal dasar yang dimiliki. Kemudian dalam RPJMD tahun 2011-2016 juga sudah disinggung sektor pertanian masih menjadi prioritas utama dalam peningkatan perekonomian di Kabupaten Pandeglang. Selain itu dari hasil evaluasi terhadap RPJMD tahun 2006-2010 didapatkan beberapa permasalahan mendasar terutama terkait belum efektifnya belanja daerah dalam menggerakkkan ekonomi lokal sekaligus perekonomian, penciptaan lapangan kerja dan perbaikan pendapatan masyarakat.

Sejalan dengan RPJP dan RPJMD Kabupaten Pandeglang, dalam RKPD Tahun 2015 sektor pertanian juga sudah mendapatkan perhatian dan prioritas oleh Pemerintah Kabupaten Pandeglang. Hal ini dapat dilihat dari tema yang diusung dalam pembanguan tahun 2015 yang menempatkan sektor pertanian dan sektor pariwisata sebagai prioritas. Adapun tema yang diusung dalam RKPD 2015 adalah "Percepatan Pembangunan Infrastruktur Dan Suprastruktur Khususnya Sektor Pertanian Dan Pariwisata".

Dari ketiga dokumen diatas tentunya sudah digambarkan dengan jelas pokok permasalahan yang dihadapi Pemerintah Kabupaten Pandeglang khususnya yang menyangkut 
pengembangan sektor pertanian sebagai sektor unggulan.

Sedangkan untuk mendeskripskan implementasi kebijakan sektor pertanian dapat dilihat dari realisasi anggaran maupun laporan kinerja Kabupaten Pandeglang. Terkait realisasi anggaran sektor pertanian tentunya dapat dilihat dari Satuan Kerja Perangkat Daerah (SKPD) yang masuk dalam urusan-urusan pada sektor pertanian. Di Kabupaten Pandeglang terdapat 4 SKPD yang termasuk dalam urusan di sektor pertanian yaitu Dinas Pertanian dan Peternakan, Dinas Kelautan dan Perikanan, Badan Ketahanan Pangan dan Penyuluhan dan Dinas Kehutanan.

Jika dilihat dari realisasi anggaran, keempat SKPD yang termasuk dalam sektor pertanian sudah cukup baik. Dinas Pertanian dan Perternakan sudah merealisasikan 91,58\% dari total anggaran Rp51.298.510.311,00. Kemudian Dinas Kelautan dan Perikanan memiliki realiasi anggaran $91,1 \%$ dari total anggaran Rp12.414.799.850,00. Badan Ketahanan Pangan dan Penyuluhan sendiri hanya dapat merealisasikan anggaran $71,6 \%$ dari total anggaran Rp 19.173.825.042,00 dengan realisasi belanja barang dan jasa hanya 59,3\%. Sedangkan Dinas Kehutanan memiliki realisasi anggaran $96,7 \%$ dari total anggaran Rp8.142.212.683,00.

\section{Pengaruh Pengeluaran Pemerintah dan Tenaga Kerja terhadap Pertumbuhan Sektor Pertanian}

Penelitian ini menggunakan data time series 2006-2015 dan cross section antar kabupaten/kota di Provinsi Banten untuk mengetahui pengaruh anggaran pemerintah sektor pertanian dan tenaga kerja sektor pertanian terhadap pertumbuhan sektor pertanian. PDRB yang digunakan adalah PDRB atas dasar harga berlaku. Sedangkan data tenaga kerja sektor pertanian merupakan penduduk usia kerja yang bekerja pada sektor pertanian. Pengeluaran pemerintah sektor pertanian sendiri merupakan data APBD Kabupaten Pandeglang yang direklasifikasi berdasarkan urusan wajib dan urusan pilihan. Adapun urusan-urusan yang masuk dalam sektor pertanian adalah bidang pertanian, pertahanan pangan, perikanan dan kelautan, dan kehutanan dan perkebunan.

Penelitian ini mengeluarkan kabupaten hasil pemekaran yaitu Kota Tangerang Selatan dan Kota Serang karena datanya tidak memenuhi jangka 10 tahun seperti yang dibutuhkan. Berikut adalah hasil regresi berganda data panel dengan mengunakan model yang paling baik digunakan yaitu model FEM di Provinsi Banten (Tabel 1). Berdasarkan Tabel 1, dapat diperoleh model persamaan umum yaitu:

$$
\begin{gathered}
\text { PRDBAgr }=3158649- \\
19.87611 * T K A g r+72.51226 * G O V A g r
\end{gathered}
$$

Berdasarkan hasil regresi data panel dengan menggunakan model FEM, maka diperoleh hasil hubungan/pengaruh antara pengeluaan pemerintah sektor pertanian dan tenaga kerja sektor pertanian terhadap PDRB sektor pertanian sebagai berikut:

1. Pengaruh tenaga kerja sektor pertanian terhadap PDRB sektor pertanian berpengaruh negatif dan signifikan dengan koefisien sebesar (-19.87611) serta nilai probalitas sebesar 0,0211 atau lebih kecil dari nilai P-value 0,05. Hal ini berarti apabila terjadi peningkatan tenaga kerja sektor pertanian sebesar satu tenaga kerja pertahun, maka akan menurunkan PDRB sektor pertanian sebesar 19,87 juta rupiah dengan asumsi variable pengeluaran pemerintah sektor pertanian (GOVAgr) dianggap konstan.

2. Pengaruh pengeluaran pemerintah sektor pertanian terhadap PDRB sektor pertanian berpengaruh positif dan signifikan dengan koefisien sebesar 72.51226 serta nilai probalitas sebesar 0,0020 atau lebih kecil dari nilai P-value 0,05 . Hal ini berarti apabila terjadi peningkatan pengeluaran pemerintah sektor pertanian sebesar satu juta rupiah pertahun, maka akan menaikkan PDRB sektor pertanian sebesar 72.512 juta 
rupiah dengan asumsi variable tenaga kerja sektor pertanian (TKAgr) dianggap konstan.

Setelah melakukan regresi data panel dengan menggunakan model yang paling baik yaitu model FEM, selanjutnya adalah melakukan pengujian terhadap model tersebut dengan menggunakan uji $\mathrm{F}$ (pengaruh secara simultan), uji $\mathrm{t}$ (uji pengaruh secara parsial), dan uji $\mathrm{R}^{2}$ (uji koefisien determinan). Berikut hasil uji stratistik tersebut:

1. Hasil uji $F$ digunakan untuk menunjukkan apakah semua variable independen yang dimasukkan dalam model mempunyai pengaruh secara simultan atau bersama terhadap variable dependen pada model. Dasil regresi data panel FEM menunjukkan probabilitas $\mathrm{F}$ $=0,0000$ yang berarti kurang dari $\alpha=$ 0,05 . Hal tersebut berarti menolak Ho dan menerima $\mathrm{H} 1$ yang artinya minimal ada satu peubah bebas yang berpengaruh terhadap responden.
2. Dari hasil uji t dapat diketahui bahwa nilai TK (X1) memiliki nilai probability sebesar 0.0211 kurang dari 0.05 . Hal tersebut berarti $\mathrm{H} 0$ ditolak, yang berarti bahwa variabel TK (X1) berpengaruh nyata terhadap variabel $\mathrm{Y}$ (PDRB Sektor Pertanian). Kemudian perhatikan pula bahwa variable GOV (X2) memiliki nilai probability sebesar 0.0020 kurang dari 0.05, yang berarti bahwa H0 ditolak. Hal tersebut berarti variabel GOV (X2) berpengaruh nyata terhadap variabel PDRB Sektor Pertanian (Y).

Kemudian dari hasil estimasi pada model regresi menunjukkan nilai nilai $R$ Square adj sebesar 0.889 yang berarti $88.9 \%$ keragaman peubah respon mampu dijelaskan oleh model, sisanya $11.1 \%$ dijelaskan oleh peubah lain diluar model regresi.

Tabel 1: Hasil Analisis Regresi Data Panel dengan Pendekatan FEM

\begin{tabular}{lcccc}
\hline Variabel & Coefficient & Std.Error & t-Statistic & Prob. \\
\hline C & 3158649 & 1303801 & 2.422647 & 0.0189 \\
TK & 37611 & 8.356418 & -2.378544 & 0.0211 \\
GOV & 72.51226 & 22.27701 & 3.255026 & 0.0020 \\
\hline Weighted Statistics & & & \\
\hline R-squared & 0.903018 & & \\
Adjusted R-squared & 0.889963 & & \\
S.E. of regression & 776533.2 & & \\
F-statistic & 69.16877 & & \\
Prob(F-statistic) & 0.000000 & & \\
\hline
\end{tabular}

\begin{tabular}{|l|l|}
\hline CROSSID & Effect \\
\hline Pandeglang & 2607038 \\
\hline Lebak & 2450176 \\
\hline Tangerang & 415670.9 \\
\hline Serang & 572447.6 \\
\hline Kota Tangerang & -2752178 \\
\hline Kota Cilegon & -3293154 \\
\hline
\end{tabular}




\section{Strategi Alokasi Anggaran dalam Pengembangan Sektor Pertanian}

\section{Identifikasi Faktor Kunci Internal dan Eksternal}

Dari hasil studi pustaka maupun wawancara dengan informan yang merupakan pihak yang terlibat langsung dalam kebijakan alokasi anggaran sektor pertanian, didapat beberapa faktor internal yang dimiliki Pemerintah Kabupaten Pandeglang.

A. Faktor Internal yang merupakan kelebihan, adalah:

1. Sumber daya yang potensial dan dapat menjadi modal dasar untuk dikembangkan. Kabupaten Pandeglang merupakan daerah yang sangat potensial bagi pengembangan sektor pertanian. Dari 274.689 hektar luas Pandeglang, 219.950 hektar $(80,07 \%)$ diantaranya digunakan untuk usaha pertanian seperti persawahan, ladang, kebun, kolam/tebat/empang, tambak, perkebunan besar, lahan untuk tanaman hutan rakyat dan hutan negara. Selain itu Kabupaten Pandeglang juga dialiri oleh 18 aliran sungai dengan panjang total $835 \mathrm{~km}$ yang dapat menjadi faktor pendukung bagi pengembangan sektor pertanian. Kabupaten Pandeglang juga memiliki pantai seluas $307 \mathrm{~km}$ yang memiliki potensi pengembangan perikanan laut. Pada sub sektor kehutanan, Kabupaten Pandeglang juga memiliki luas hutan sebanyak 115.373,90ha atau $42 \%$ dari luas total Kabupaten Pandeglang.

2. Komitmen pemerintah daerah Kabupaten Pandeglang yang tinggi dan sudah memberikan prioritas bagi sektor pertanian. Hal ini dapat dilihat dari berbagai dokumen perencanaan yang menempatkan sektor pertanian sebagai sektor yang prioritas, baik itu dalam RPJP, RPJMD Tahun 2011-2016, maupun dalam RKPD Tahun 2015. Bahkan pengembangan sektor pertanian menjadi visi bagi pemerintah Kabupaten Pandeglang.
3. Menjadi daerah prioritas dalam percepatan pembangunan sehingga mendapatkan dukungan anggaran (DAK) yang paling besar di Provinsi Banten.

4. Dukungan legislatif yang baik. Sejauh ini komisi II DPRD Kabupaten Pandeglang sudah memberikan dukungan yang baik pada sektor pertanian.

B. Faktor Internal yang merupakan kelemahan, adalah:

1. Dukungan anggaran yang kecil untuk sektor pertanian. Sektor pertanian memang sudah dijadikan sebagai sektor prioritas dalam mempercepat pembangunan di Kabupaten Pandeglang. Hal ini terlihat dari beberapa dokumen perencanaan yang dimiliki Kabupaten Pandeglang. Namun pada kenyataannya dukungan anggaran terhadap sektor pertanian masih kecil, berkisar dalam angka $2 \%$.

2. Efektifitas pengeluaran pemerintah sektor pertanian yang belum terlaksana. Sampai sejauh ini, seperti yang telah diidentifikasikan juga pada RPJMND Tahun 2011-2016.

3. Kualitas SDM yang masih rendah. Jumlah tenaga kerja sektor pertanian di Kabupaten Pandeglang sebanyak 189.384 orang, namun secara kualitas masih rendah

4. Inovasi dan penggunaan tehnologi di sektor pertanian masih terbatas. Sektor pertanian di Kabupaten Pandeglang masih dijalankan secara tradisional baik itu subsektor pertanian itu sendiri, perikanan, perkebunan, dan kehutanan.

5. Kurang terintegrasi sektor pertanian dengan sektor-sektor lainnya.

Dari hasil studi literatur maupun analisis data yang sudah dilakukan, berikut beberapa faktor eksternal yang dimiliki Pemerintah Kabupaten Pandeglang:

A. Faktor eksternal yang merupakan peluang, adalah:

1. Posisi geografis yang berdekatan dengan ibukota negara. Jila dilihat dari aspek envionment, Kabupaten Pandeglang berjarak $\pm 111 \mathrm{Km}$ dari 
Jakarta yang merupakan ibukota negara dan juga pusat perekonomian. Hal tersebut merupakan hal yang menguntungkan karena jika dapat membangun sistem distribusi hasil sektor pertanian yang baik akan mampu mempercepat pertumbuhan ekonomi daerah.

2. Perlunya untuk meningkatkan peran swasta dalam mendukung pengembangan sektor pertanian. Jika dilihat dari aspek competition, tidak hanya Kabupaten Pandeglang yang mampu menghasilkan produk-produk sektor pertanian. Sementara itu, anggaran pemerintah Kabupaten Pandeglang untuk pengembangan sektor pertanian sangat terbatas. Oleh karena itu, pemerintah daerah Kabupaten Pandeglang perlu untuk melibatkan pihak swasta.

3. Meningkatkan kerjasama dengan perguruan tinggi, maupun instansi vertikal dalam upaya penerapan tehnologi tepat guna bagi sektor pertanian. Hal ini dikarenakan salah satu permasalahan pengembangan sektor pertanian adalah penggunaaan tehnologi yang sangat minil dan masih sangat tradisional.

4. Komitmen dari pemerintah pusat dalam mendukung pengembangan sektor pertanian. Dari aspek politik, dukungan pemerintah pusat dalam upaya mempercepat pembangunan daerah di Kabupaten Pandeglang terlihat dari RPJM Nasional tahun 2011-2016 yang menyebutkan daerah tertinggal mendapatkan prioritas pembangunan.

5. Kerjasama antar daerah untuk membangun jaringan dalam distribusi hasil sektor pertanian. Kemampuan untuk distribusi hasil sektor pertanian tidak kalah pentingnya dengan memproduksi hasil sektor pertanian. Oleh karena itu sangat penting membangun kerjasama dengan daerah lain terutama daerah bukan penghasil sektor pertanian untuk memperluas pasar.
B. Faktor eksternal yang merupakan ancaman, adalah:

1. Budaya masyarakat yang resisten terhadap hal-hal yang baru.

2. Berbagai kemajuan pembangunan sektor pertanian yang dimiliki oleh daerah lain. Dilihat dari aspek competition, setiap daerah akan bersaing dengan daerah lainnya terlebih bagi daerah yang memproduksi hal yang homogen. Oleh karena itu, kemajuan pembangunan sektor pertanian di daerah lain dapat menjadi ancaman bagi pengembangan sektor pertanian di Kabupaten Banten.

3. Dampak pemotongan anggaran. Terkait kebijakan ini, berasal dari Pemerintah Pusat yang tidak bisa diprediksi. Kondisi ini menjadi ancaman bagi pemerintah daerah Kabupaten Pandeglang, karena sampai saat ini ketergantungan Pemda Kabupaten Pandeglang kepada pemerintah pusat masing sangat tinggi.

4. Kondisi infrastruktur di Kabupaten Pandeglang yang masih sangat terbatas. Hal ini menjadi ancaman tersendiri bagi pengembangan sektor pertanian. Hasil produksi pertanian seringkali tidak dapat didistribusikan dengan baik karena kondisi wilayah di Kabupaten Pandeglang yang sangat minim dengan insfrastruktur.

5. Kepercayaan pihak perbankan terhadap masyarakat di Kabupaten Pandeglang dalam pemberian kredit usaha rakyat yang rendah. Dari hasil analisis melalui wawancara dengan beberapa informan, dapat diketahui kondisi kepercayaan perbankan dalam pemberikan kredit untuk mendukung permodalan di Kabupaten Pandeglang rendah. Dari data yang disampaikan oleh Bank BRI yang merupakan perbankan yang paling banyak digunakan di Kabupaten Pandeglang, jumlah kredit macet di Kabupaten Pandeglang terhitung tinggi. 


\section{Perumusan Alternatif Strategi Melalui Analisis SWOT}

Dengan mengetahui isu-isu strategis apa yang menjadi faktor internal yang meliputi kekuatan dan kelemahan serta faktor eksternal yang meliputi peluang dan tantangan, tentunya akan dapat dirumuskan alternatif strategi yang tepat dalam pengembangan sektor pertanian. Strategi ini didasarkan pada analisis SWOT berdasarkan hasil wawancara dengan beberapa pihak yan mengetahui dengan baik kondisi di Kabupaten Pandeglang. mAdapun perumusan strategi disusun berdasarkan kombinasi faktor internal yang terdiri dari kekuatan dan kelemahan serta faktor eksternal yang terdiri dari peluang dan ancaman ke dalam matriks SWOT seperti disajikan pada Tabel 3 sebagai berikut:

\section{Tabel 3: Matriks SWOT dan Alternatif Strategi Pengembangan Sektor Pertanian}

\begin{tabular}{|c|c|c|}
\hline & $\mathbf{S}-$ KEKUATAN & W - KELEMAHAN \\
\hline EFE & $\begin{array}{l}\text { 1. Sumber daya yang potensial dan dapat } \\
\text { menjadi modal dasar untuk } \\
\text { dikembangkan } \\
\text { 2. Komitmen pemerintah daerah } \\
\text { Kabupaten Pandeglang yang tinggi } \\
\text { dan sudah memberikan prioritas bagi } \\
\text { sektor pertanian } \\
\text { 3. Menjadi daerah prioritas dalam } \\
\text { percepatan pembangunan sehingga } \\
\text { mendapatkan dukungan anggaran } \\
\text { (DAK) paling besar di Provinsi } \\
\text { Banten } \\
\text { 4. Dukungan legislatif yang baik dan } \\
\text { mendukung pengembangan sektor } \\
\text { pertanian }\end{array}$ & $\begin{array}{l}\text { 1. Dukungan anggaran yang kecil } \\
\text { untuk sektor pertanian } \\
\text { 2. } \begin{array}{l}\text { Efektifitas pengeluaran pemerintah } \\
\text { sektor pertanian yang belum } \\
\text { terlaksana }\end{array} \\
\text { 3. Kualitas SDM masih rendah (baik } \\
\text { itu aparatur di sektor pertanian } \\
\text { maupun tenaga kerja di sektor } \\
\text { pertanian) } \\
\text { 4. Inovasi dan penggunaan tehnologi } \\
\text { yang masih terbatas } \\
\text { Kurang terintegrasi sektor } \\
\text { pertanian dengan sektor-sektor } \\
\text { lainnya. }\end{array}$ \\
\hline O - PELUANG & $\begin{array}{c}\text { STRATEGI }(\mathrm{S}-\mathrm{O}) \\
\end{array}$ & STRATEGI $(\mathbf{W}-\mathbf{O})$ \\
\hline $\begin{array}{l}\text { 1. Posisi geografis yang strategis } \\
\text { karena berdekatan dengan } \\
\text { ibukota negara } \\
\text { 2. Perlunya peningkatan peran } \\
\text { swasta untuk mendukung } \\
\text { pengembangan sektor pertanian } \\
\text { 3. Meningkatkan kerjasama dengan } \\
\text { perguruan tinggi, maupun } \\
\text { instansi vertikal dalam upaya } \\
\text { penerapan tehnologi tepat guna } \\
\text { bagi sekor pertanian } \\
\text { 4. Komitmen dari pemerintah pusat } \\
\text { yang mendukung pengembangan } \\
\text { sektor pertanian } \\
\text { 5. Kerjasama antar daerah untuk } \\
\text { membangun jaringan dalam } \\
\text { distribusi hasil sektor pertanian }\end{array}$ & $\begin{array}{l}\text { 1. Pengelolaan sektor pertanian dengan } \\
\text { melibatkan berbagai pihak seperti } \\
\text { pihak swasta untuk pembiayaan, } \\
\text { akademisi untuk dukungan } \\
\text { penggunaan tehnologi tepat guna } \\
(\mathrm{O} 2, \mathrm{O} 3, \mathrm{~S} 1) \\
\text { 2. Membangun kerjasama antar daerah } \\
\text { untuk memperluas pasar (S1, O5) } \\
\text { 3. Memperbaiki sistem pengawasan } \\
\text { dalam implementasi program- } \\
\text { program pada sektor pertanian agar } \\
\text { anggaran bisa memberikan outcome } \\
\text { yang optimal (S3, S4, O4) }\end{array}$ & $\begin{array}{l}\text { 1. Membangun kerjasama dengan } \\
\text { sektor swasta (W1,O2) } \\
\text { 2. Mengadakan bimbingan dan } \\
\text { pelatihan kepada penyuluh maupun } \\
\text { tenaga kerja sektor pertanian secara } \\
\text { langsung melalui kerjasama dengan } \\
\text { akademisi (W3, O3) } \\
\text { 3. Membangun sinergi dan kerjasama } \\
\text { antara sektor pertanian dengan } \\
\text { sektor-sektor lainnya (W5, O5) }\end{array}$ \\
\hline T - ANCAMAN & STRATEGI $(\mathrm{S}-\mathrm{T})$ & STRATEGI $(\mathbf{W}-\mathrm{T})$ \\
\hline $\begin{array}{l}\text { 1. Kondisi budaya masyarakat } \\
\text { yang resisten terhadap hal-hal } \\
\text { yang baru } \\
\text { 2. Berbagai kemajuan } \\
\text { pembangunan sektor pertanian } \\
\text { yang dimiliki daerah lain } \\
\text { 3. Dampak pemotongan anggaran } \\
\text { 4. Kondisi infrastruktur yang tidak } \\
\text { memadai khususnya di pedesaan } \\
\text { Kepercayaan perbankan yang } \\
\text { rendah dalam pemberikan } \\
\text { kredit kepada masyarakat }\end{array}$ & $\begin{array}{l}\text { 1. Memperbaikin infrastruktur di } \\
\text { daerah-daerah khususnya daerah } \\
\text { pedesaan agar hasil produksi sektor } \\
\text { pertanian bisa didistribusikan dengan } \\
\text { baik. (S1,T3) } \\
\text { 2. Memperbaiki sistem pengelolaan } \\
\text { sektor pertanian agar hasil produksi } \\
\text { dapat meningkat dan mampu bersaing } \\
\text { dengan daerah penghasil sektor } \\
\text { pertanian yang lain (S1 T1, T2) } \\
\text { 3. Penggunaan anggaran secara efektif } \\
\text { dan efisien (S4,T3) }\end{array}$ & $\begin{array}{l}\text { 1. Memperbaiki pengawasan pada } \\
\text { pengeluaran pemerintah agar dapat } \\
\text { efektif terutama terkait penyiapan } \\
\text { infrastruktur di daerah (W2, T4) }\end{array}$ \\
\hline
\end{tabular}




\section{SIMPULAN DAN SARAN}

\section{Simpulan}

1. Berdasarkan analisis deskriptif dapat digambarkan bahwa sektor pertanian sudah menjadi prioritas dalam dokumen perencanaan baik RPJPD, RPJMD, maupun RKPD Kabupaten Pandeglang. Namun saat ini Pemerintah Kabupaten Pandeglang masih menyiapkan infrastruktur agar berbagai sektor dan fungsi pelayanan dapat berjalan. Hal tersebut menyebabkan anggaran sektor pertanian masih kecil.

2. Berdasarkan hasil regresi berganda dengan menggunakan data panel dapat dihasilkan bahwa pengeluaran pemerintah berpengaruh positif dan signifikan dalam pertumbuhan ekonomi secara regional di Provinsi Banten. sementara itu tenaga kerja sektor pertanian berpengaruh negatif dan signifikan terhadap pertumbhan ekonomi secara regional di Provinsi Banten.

3. Berdasarkan hasil analisis SWOT yang dilakukan terhadap faktor internal menunjukkan bahwa Pemerintah Kabupaten Pandeglang memiliki kelemahan yang lebih besar jika dibandingkan kekuatannya. Sementara itu jika dilihat dari faktor eksternal, masih banyak peluang yang perlu ditingkatkan dengan meminimalisasi ancaman yang ada.

4. Strategi yang harus dilaksanakan terkait pengembangan sektor pertanian harus dilakukan dengan komprehensif dengan melibatkan berbagai sektor lainnya.

\section{Saran}

1. Untuk mempercepat pembangunan daerah di Kabupaten Pandeglang perlu dukungan dan kerjasama berbagai pihak baik secara internal maupun eksternal. Penguatan dan optimalisasi hasil sektor pertanian perlu dilakukan dengan didukung oleh berbagai sektor lainnya. Sementara itu infrastruktur juga perlu dibenahi sehingga memudahkan distribusi hasil sektor pertanian.

2. Sebagai tangan terdekat dengan tenaga kerja sektor pertanian, peran penyuluh menjadi sangat penting. Penyuluh merupakan representatif pemerintah daerah yang melakukan kegiatan pembinaan dan pendampingan dari mulai penentuan bibit atau benih yang sesuai dengan kondisi lapangan, perawatan dan pemeliharaan yang tepat sampai pada saat panen. Selain itu pemerintah juga perlu mengupayakan untuk memutus rantai sistem ijon yang sering dilakukan oleh pelaku sektor pertanian dengan tengkulak. Hal ini selain merugikan petani juga mempersempit pasar bagi hasil sektor pertanian tersebut.

3. Dalam alokasi anggaran, prioritas saat ini penyiapan infrastruktur yang mendukung sektor pertanian sudah dilakukan. Pemerintah daerah Kabupaten Pandeglang perlu melakukan pengawasan yang ketat terhadap proyekproyek pengadaa infrastruktur. Hal ini dikarenakan, beberapa pengadaan infratsruktur tidak sesuai dengan kesepakatan dan juga beberapa tidak selesai hingga tahun anggaran selesai. Untuk mengantisipasi hal tersebut, perlu dilakukan monitoring belanja modal secara berkala untuk memastikan proyek infrastruktur khususnya yang mendukung sektor pertanian dapat terlaksana. Pemerintah juga perlu memberikan sangksi yang tegas kepada kontraktor yang terbukti tidak menjalankan kewajibannya menyelesaikan proyek sesuai ketentuan maupun yang mengurangi kualitas hasil.

4. Terkait penelitian selanjutnya, perlu dilakukan penelitian tentang komoditas yang sesuai dengan kondisi lapangan serta tehnologi yang tepat untuk digunakan di Kabupaten Pandeglang. Selain itu kajian terkait implementasi kebijakan juga perlu dilakukan agar program-program yang sudah dirancang 
mampu memberikan dampak yang nyata terhadap perekonomian masyarakat.

\section{DAFTAR PUSTAKA}

Adisasmita R. 2010. Pengelolaan Pendapatan dan Anggaran Daerah. Yoygakarta: Graha Ilmu.

2011. Pembiayaan

Pembangunan Daerah. Yoygakarta:

Graha Ilmu.

Badan Pusat Statistik. 2015. Produk Domestik Regional Bruto Kabupaten/Kota di Indonesia 2011-2015. Jakarta: BPS

David FR. 2015. Strategic Management: Concepts and Cases. 15th Ed. Essex (GB): Pearson Education Limited.

Eliza Y. 2015. Pengaruh Pengeluaran Pemerintah, Investasi dan Angkatan Kerja Terhadap Pertumbuhan Ekonomi di Sumatera Barat. Seminar Nasional Ekonomi dan Manajemen Akuntansi (SNEMA 2015) Universitas Negeri Padang. ISBN 978-602-17129-5-5: $125-$ 131

Firdaus M. 2011. Aplikasi Ekonometrika Untuk Data Panel dan Time Series. Bogor: IPB Press.

Juanda B, Junaidi. 2012. Ekonometrika Deret Waktu: Teori dan Aplikasi. Bogor: IPB Press.

Kuncoro M. 2004. Otonomi dan Pembangunan Daerah. Jakarta: Erlangga.

Kuncoro M. 2009. Metode Riset untuk Bisnis dan Ekonomi (Bagaimana Meneliti dan Menulis Thesis) ed.3.Yogyakarta: Erlangga.

Kuncoro M. 2003. Ekonomi Pembangunan (Teori, Masalah dan Kabijakan) edisi ketiga. Yogyakarta: UPP AMP YKPN

Mahmudi. 2010. Manajemen Keuangan Daerah. Yogyakarta: Gelora Angkasa Pratama.

Mangkoesoebroto G. 1997. Ekonomi Publik. $3^{\text {rd }}$ ed. Yogyakarta (ID): BPFE

Mindrajaya I.G.N. 2009. Kajian Analisis Regresi dengan Data Panel. Yogyakarta : Universitas Negeri Yogyakarta.
Priadana H.M.S., Muis S. 2009. Metodologi Penelitian Ekonomi dan Bisnis ed.1. Yogyakarta: Graha Ilmu

Pemerintah Daerah Kabupaten Pandeglang. 2010. Peraturan Daerah Kabupaten Pandeglang Nomor 8 Tahun 2010 tentang Rencana Pembangunan Jangka Panjang Daerah Kabupaten Pandegang Tahun 2005-2025. Sekretariat Daerah Kabupaten Pandeglang

Pemerintah Daerah Kabupaten Pandeglang. 2011. Peraturan Daerah Kabupaten Pandeglang Nomor 9 Tahun 2011 tentang Rencana Pembangunan Jangka Menengah Tahun 2011-2016. Sekretariat Daerah Kabupaten Pandeglang

Pemerintah Daerah Kabupaten Pandeglang. 2011. Peraturan Daerah Kabupaten Pandeglang Nomor 9 Tahun 2011 tentang Rencana Pembangunan Jangka Menengah Tahun 2011-2016. Sekretariat Daerah Kabupaten Pandeglang

Pemerintah Daerah Kabupaten Pandeglang. 2014. Peraturan Bupati Pandeglang Nomor 14 Tahun 2014 tentang Rencana Kerja Pemerintah Daerah 2015. Sekretariat Daerah Kabupaten Pandeglang

Pemerintah Daerah Provinsi Banten. 2010. Peraturan Daerah Provinsi Banten Nomor 02 Tahun 2010 tentang Rencana Pembangunan Jangka Panjang Daerah Provinsi Banten. Sekretariat Daerah Provinsi Banten

Rahayu SR. 2011. Analisis Pengeluaran Pemerintah Terhadap Pertumbuhan Ekonomi. Jurnal Manajemen dan Bisnis Vol 11 No 02 Oktober 2011 ISSN 16937619: 126-138

Rangkuti F. 2014. Teknik Membedah Kasus Bisnis: Analisis SWOT. Jakarta (ID): PT Gramedia Pustaka Utama.

Sugiyono. 2013. Metode Penelitian Kombinasi. Bandung [ID]: Alfabeta Bandung.

Taufiq M, Purnomo S R, Viphindrartin S. 2016. Pengaruh Pengeluaran Pemerintah di Sektor Pertanian Terhadap PDRB Sektor Pertanian di Wilayah EKS Karasidenan Besuki. Jurnal FE Universitas Jember. Jember: Universitas Jember. 